Journal of Social Sciences 5(2): 95-103, 2009

ISSN 1549-3652

(C) 2009 Science Publications

\title{
Philosophy Underlying Emotional Intelligence in Relation to Level of Curiosity and Academic Achievement of Rural Area Students
}

\author{
Aminuddin Hassan, Tajularipin Sulaiman and Rohaizan Ishak \\ Faculty of Educational Studies, Universiti Putra Malaysia, \\ 43400 UPM Serdang, Selangor, Malaysia
}

\begin{abstract}
Problem statement: Since emotional intelligence is still not wholly-accepted despite evidences of its powerful influence in general setting, this study is therefore conducted to identify the emotional intelligence level among school students in rural areas, relationships between emotional intelligence and anxiety, as well as relationships between emotional intelligence and academic achievement. Approach: It involved a sample of 223 form 1 and form 4 students. Process of data collection was administered by using a set of questionnaire which includes a self report measure of emotional intelligence adapted from Schutte Self-Report of Emotional Intelligence (SSRI) and Beck Anxiety Inventory (BAI). T-test analysis showed that there were no significant differences for the emotional intelligence level within all students between ages 13 and 16. However, there were significant differences for the emotional intelligence level among female students in accordance to age. Results: The results showed that there were significant differences for emotional intelligence level among all students between both genders. Mean score of emotional intelligence within female students appeared to be higher than male students. Pearson correlation analysis showed that emotional intelligence levels of all students were significant negatively in relation to anxiety level. Emotional intelligence was also significant positively in correlation with academic achievement of all variables including students' age and gender. Conclusion: Besides emotional intelligence, the study revealed that anxiety was also significantly correlated in a negative manner with academic achievement among all students.
\end{abstract}

Keywords: Philosophy of education, emotional intelligence, anxiety and academic achievement

\section{INTRODUCTION}

The national philosophy of education (1987) outlined a number of key factors that need to be implemented in the education field in order to produce individuals that are intellectually, spiritually, emotionally and physically balanced. Emotional intelligence is deemed as one of the important aspects in educating a person to be balanced as a whole. Through emotional intelligence, one will become more successful in life as compared to individuals that gain solely high levels of intellectual intelligence (IQ) $)^{[17]}$. Emotional intelligence also provides liberty for individuals to explore self potentials, as well as providing opportunities for individuals to harmonize themselves with their self emotion. In other words, individuals with high levels of emotional intelligence are those that are able to manage their emotions well ${ }^{[25]}$.

The awareness towards the importance of the role of emotional intelligence sparked numerous studies which are interconnected with human emotions in various perspectives of life. Every effort in accommodating towards an adjustment will create several problems. The way to solve problems is mainly based on the experience which is already gained by individuals through the process of interaction with their surroundings. In the process of development in today's modern era, individuals will then encounter several situations, which later on will result with them creating various problems. The problems of adjustment occur because of the existence of conflict towards humans themselves, in order to fulfill the need of their surroundings.

Hurlock $^{[20]}$ suggests that the problem of emotion also needs to be looked from the aspect of its impact towards the individual, society, as well as the state. Highly emotional disturbances are not only influencing the behavior, but also attitude, psychological conditions, as well as their abilities. The authority should be given to the teenagers as youth age is known

Corresponding Author: Aminuddin Hassan, Faculty of Educational Studies, Universiti Putra Malaysia, 43400 UPM Serdang, Selangor, Malaysia 
as a phase of 'storm and stress'; where emotional disturbances frequently occur, accompanied by rapid physical growth and the varied levels of psychological growth. The difficulty at teenage phase especially at the stage of puberty (11 years old to 16 years old) may cause teenagers to face difficulties in coping with the next stages of growth ${ }^{[20]}$.

The term 'emotional intelligence' was coined by Peter Salovey from University of Yale and John Mayer from University of New Hampshire in 1990. According to Salovey and Mayer ${ }^{[29]}$, emotional intelligence is the ability to manage individual self and other people from the aspect of feeling and emotion, able to distinguish the two terms apart and able to use the information to guide one's thinking and act. Emotional intelligence also depicts an amount of competence which relates with the ability to control emotion in order to motivate, to feature and to gain purpose in life ${ }^{[2]}$.

According to Goleman ${ }^{[17]}$, emotional intelligence is an ability to understand the self emotion and applies the talent to make effective decisions in life. With emotional intelligence, an individual is able to contain disappointments, sadness and other negative feelings in a positive manner. Emotional intelligence also enables an individual to control self-impetus. Furthermore, according to Goleman, the level of IQ contributes only about $20 \%$ towards one's accomplishment, while the rest are determined by emotional intelligence ${ }^{[17]}$. Emotional intelligence is also deemed as a group of several factors of one's social and cognitive aspects and the connection within the description of emotion ${ }^{[30]}$.

Anxiety on the contrary, is defined as the strength of the feeling of disturbances, subjectivity, uncertainty, nervousness endured by individuals in one time and the increase of automatic neuron activity, as a result of this feeling. The condition of anxiety is different from its strength and the duration is based on the strain that has been endured by the individual according to self interpretation whether the situation is hazardous and threatening to the self or not. Anxiety is part and parcel of life and one of the psychological conditions of uncertainty which happens frequently. It also refers to the obscure feeling and uncomfortable state of fearing that something terrible would happen ${ }^{[21]}$. Concisely, anxiety is pictured as self perception, which is connected with uncertainty towards the ability to overcome the needs of a situation ${ }^{[18]}$.

Statement of the problem: In entirety, our national education system is based on academic intelligence and highly logically and analytically technical aspects. The curriculum field is adorned based on the need of grammar, mathematic, sanity, orientation of formula and group of fact and cart. However, the premise is not entirely practical ever since the last decade. There are facts that show that not all individuals with highly academic achievements gain successful accomplishments in their careers and personal lives. Mayer and Salovey ${ }^{[23]}$ found out that those with high levels of cognitive intelligence (IQ) are not assured of excelling in their careers. Moreover, some of them which are successful in career and personal life are actually those with middle achievement and it is not uncommon for some thriving with only basic education.

The factor of emotional intelligence is looked as one of the factors that influence students' learning process. Evidently, emotional intelligence contributes significant an implication towards their academic achievements $^{[5,28]}$. In general context, excellence in academic achievement has been commonly connected with students' high cognitive intelligence, while the aspect of emotion has not been given its deserving emphasis. Thus, the study of emotional intelligence needs to be widened to open up the minds of parents, teachers and the authority that are directly and indirectly involved in the process of development and learning of the students. The objective should focus on the importance of emotional intelligence towards the inner soundness and successes of their children.

In some cases, the factor of emotional intelligence is also interconnected with the aspect of one's anxiety. Studies have found out that high levels of emotional intelligence is able to decrease the level of anxiety of an individual $^{[8,10,14]}$. Aspects of anxiety on the other hand, are closely connected with expansion, attention, motivation and a large number of components in an individual's emotion $^{[15]}$. Unsurprisingly, lower levels of anxiety have been proven to be able to improve students' academic achievement ${ }^{[12,37]}$.

The condition of anxiety exists as a result of feeling of fear and the hate for risks. Anxiety could also become a possible impediment in the learning process $^{[33]}$. It has been proven to weaken the achievement of cognitive functions, including attention, memory, formations of concepts and problem-solving. Furthermore, there is a connection between anxiety and the aspect of difficulty in carrying out a task, where the anxiety constructs a weak achievement in complex task, but increase the level of achievement in easy task ${ }^{[34]}$.

Objective of the study: The objective of the study in general is to look at the level of emotional intelligence and its relation with the level of anxiety, as well as academic achievement among the students in one of the rural area schools. Explicitly, the objectives of the study are as follow: 
- To look at the differences in level of emotional intelligences based on students' age, that is between 13 and 16 year old students

- To look at the differences in level of emotional intelligence according to students' gender

- To look at the relation between the emotional intelligence levels with the level of anxiety among students

- To look at the relation between the level of emotional intelligence with the academic achievement among students

- To look at the relation between the level of anxiety with the academic achievement among students

\section{MATERIALS AND METHODS}

The study is entirely based on a survey using a questionnaire towards 223 secondary school students, which are 13 year old and 16 year old of age. The technique of purposive sampling is used to fulfill the study's objective, which is cannot be done by using the random sampling technique ${ }^{[32]}$.

Instrument of the research: The set of questionnaire consists of 3 parts, that is Part A (Self Information), Part B (Emotional Intelligence) and Part C (Level of Anxiety). A survey of the level of emotional intelligence is based on the survey of Schutte SelfReport of Emotional Intelligence ${ }^{[30]}$. SSRI consist of 33 items which is able to measure the self report regarding to emotional intelligence based on Mayer and Salovey's model of emotional intelligence. The group of item which has been constructed to measure the emotional intelligence in the scale of SSRI is based on four basic domains in the model of emotional intelligence by Mayer and Salovey, which are the assessment and statement of emotion, the using of emotion and social skill ${ }^{[13]}$. The marking scheme is doing by referring to the total score for all positive and negative items. There are only 3 negative items in the scale, which is item 5, 28 and item $33^{[30]}$.

The value of trustworthiness which has been reported by Schutte and friends ${ }^{[30]}$ in the scale of emotional intelligence's measurement is 0.90. In previously studies which had been conducted to determine the authenticity value of SSRI measurement scale, the researchers have acquiring a significant value of correlation when analysis of correlation and others equivalent assessment were conducted. For example, by looking at the analysis of SSRI correlation with five factor model the result shows there is significant relation between both appliances of the analysis, which have reporting the correlation value until 0.51 for every involved factors ${ }^{[22]}$. Moreover, the score for the whole emotional intelligence correlate in negative way and stable with the Scale of Toronto Alexithymia, that is $r=-0.65^{[30]}$. The score also has positive correlation with the measurement of positive emotion, that is $r=0.55^{[31]}$.

Furthermore, the measurement of anxiety's level among the respondents is conducted by using Beck Anxiety Inventory (BAI). BAI had been produced $\mathrm{Beck}^{[9]}$ to recognize the symptoms and the level of anxiety of individual. BAI is an appliance of measurement towards anxiety with popularly and extendedly used because it is more efficient, economic, easy to be use, comprehensive and easy to be interpreted $^{[16]}$. BAI consist of high level of trustworthiness, which is 0.91 . The test of trustworthiness and re-test are around 0.35-0.83 with the average of $0.66^{[16]}$. Study by De Ayala, et al.$^{[16]}$ that using BAI instrument towards college students as the respondents had found that the value of trustworthiness is 0.90. Furthermore, the authenticity of BAI instrument also states the high value. This is also can be proved through the series of studies to look at the authenticity of BAI instrument, which show the value of correlation is around 0.47 until 0.81 when the analysis of correlation and equivalent instrument has been conducted. For example, cognition checklist anxiety subscale, state trait inventory, anxiety subscale of the symptom checklist 90-revised, hamilton rating scale for anxiety and anxiety diaries ${ }^{[16]}$.

\section{RESULTS}

The Difference of emotional intelligence's level based on the age of student: The difference of emotional intelligence level based on the age of student from entirely view is shown in Table 1 . Analysis of $t$ experiment shows that there is a significant difference towards the level of emotional intelligence among the 13 years old student with 16 years old student, $\mathrm{t}(221)=0.08 ; \mathrm{p}>0.05$.

Table 2 shows the difference of emotional intelligence level based on age of male student.

Table 1: The Difference of emotional intelligence level based on the age of student from entirely view

\begin{tabular}{lllllll}
\hline Age & $\mathrm{N}$ & $\mathrm{Min}$ & $\mathrm{sp}$ & $\mathrm{dk}$ & $\mathrm{t}$ & $\mathrm{p}$ \\
\hline 13 years & 100 & 3.20 & 0.52 & 221 & 0.08 & 0.94 \\
16 years & 123 & 3.19 & 0.61 & & & \\
\hline
\end{tabular}

Table 2: The difference of emotional intelligence level based on age of male student

\begin{tabular}{lllllll}
\hline Age & $\mathrm{N}$ & Min & $\mathrm{sp}$ & $\mathrm{dk}$ & $\mathrm{t}$ & $\mathrm{p}$ \\
\hline 13 years & 52 & 3.10 & 0.54 & 124 & 1.24 & 0.22 \\
16 years & 74 & 2.97 & 0.59 & & & \\
\hline
\end{tabular}


Table 3: The difference of emotional intelligence level based on age of female student

\begin{tabular}{lllllll}
\hline Age & $\mathrm{N}$ & Min & $\mathrm{sp}$ & $\mathrm{dk}$ & $\mathrm{t}$ & $\mathrm{p}$ \\
\hline 13 years & 48 & 3.30 & 0.48 & 95 & 2.28 & 0.03 \\
16 years & 49 & 3.52 & 0.47 & & & \\
\hline *: $\mathrm{p}<0.05$ & & & & & &
\end{tabular}

Table 4: The difference of emotional intelligence level based on the gender of student from entirely view

\begin{tabular}{lllllll}
\hline Gender & $\mathrm{N}$ & Min & $\mathrm{sp}$ & $\mathrm{dk}$ & $\mathrm{t}$ & $\mathrm{p}$ \\
\hline Male & 126 & 3.02 & 0.57 & 221 & 5.35 & 0.000 \\
Female & 97 & 3.41 & 0.48 & & & \\
\hline$*: \mathrm{p}<0.05$ & & & & & &
\end{tabular}

Analysis of $\mathrm{t}$ experiment shows that there is no significant difference towards the level of emotional intelligence among the 13 years old male student with 16 years old male student, $\mathrm{t}(124)=1.24 ; \mathrm{p}>0.05$.

Table 3 has shows the difference of emotional intelligence level based on age of female student. Analysis of $t$ experiment shows that there is significant difference towards the level of emotional intelligence among the 13 years old female student with 16 years old female student, $\mathrm{t}(95)=2.28 ; \mathrm{p}<0.05$.

The difference of emotional intelligence level based on the gender of student: The difference of emotional intelligence level based on the gender of student from entirely view is shown in Table 4. Analysis of $t$ experiment shows that there is a significant difference between the mean score on the level of emotional intelligence among male student with female student, $\mathrm{t}$ $(221)=5.35 ; \mathrm{p}<0.05$.

Table 5 has shows the difference of emotional intelligence level based on the gender of 13 years old student. Analysis of $t$ experiment shows that there is no significant difference towards the level of emotional intelligence among the 13 years old male student with female student in the same category of age, $\mathrm{t}(98)=1.97 ; \mathrm{p}>0.05$.

Table 6 has shows the difference of emotional intelligence level based on the sex of 16 years old student. Analysis of t experiment shows that there is a significant difference towards the level of emotional intelligence among the 16 years old female student with 16 years old male student female student, $\mathrm{t}(121)=5.45$; $\mathrm{p}<0.05$.

The relation between the levels of emotional intelligence with the level of anxiety among rural area students: Table 7 shows the relation between the levels of emotional intelligence with the level of anxiety among rural area students from entirely view. Analysis of correlation shows that there is significant of negative relation between emotional intelligence with the level of anxiety among students, which has become the subject of the study, $r=-0.60 ; p<0.01$.
Table 5: The difference of emotional intelligence level based on the gender of 13 years old student

\begin{tabular}{lllllll}
\hline Gender & $\mathrm{N}$ & Min & $\mathrm{sp}$ & $\mathrm{dk}$ & $\mathrm{t}$ & $\mathrm{p}$ \\
\hline Male & 52 & 3.10 & 0.54 & 98 & 1.97 & 0.052 \\
Female & 48 & 3.30 & 0.48 & & & \\
\hline
\end{tabular}

Table 6: The difference of emotional intelligence level based on the gender of 16 years old student

\begin{tabular}{lllllll}
\hline Gender & $\mathrm{N}$ & $\mathrm{Min}$ & $\mathrm{sp}$ & $\mathrm{dk}$ & $\mathrm{t}$ & $\mathrm{p}$ \\
\hline Male & 74 & 2.97 & 0.59 & 121 & 5.45 & 0.000 \\
Female & 49 & 3.52 & 0.47 & & & \\
\hline
\end{tabular}

$*: \mathrm{p}<0.01$

Table 7: The relation between the levels of emotional intelligence with the level of anxiety among rural area students from entirely view

\begin{tabular}{lll}
\hline & \multicolumn{2}{c}{ Anxiety } \\
Variable & $\mathrm{r}$ & $\mathrm{p}$ \\
\hline Emotional Intelligence & -0.60 & $0.000^{*}$ \\
\hline$*: \mathrm{p}<0.01$ & &
\end{tabular}

Table 8: The relation between the levels of emotional intelligence with the level of anxiety based on the group of age

\begin{tabular}{llc}
\hline & \multicolumn{2}{c}{ Anxiety } \\
Variable & -----1 & $\mathrm{p}$ \\
\hline 13 years old Student & -0.73 & $0.000^{*}$ \\
16 years old Student & -0.64 & $0.000^{*}$ \\
\hline *: $\mathrm{p}<0.01$ & &
\end{tabular}

Table 9: The relation between the levels of emotional intelligence with the levels of anxiety based on gender

\begin{tabular}{|c|c|c|}
\hline \multirow[b]{2}{*}{ Variable } & \multicolumn{2}{|c|}{ Anxiety } \\
\hline & $\mathrm{r}$ & $\mathrm{p}$ \\
\hline Male & -0.63 & $0.000^{*}$ \\
\hline Female & -0.52 & $0.000 *$ \\
\hline
\end{tabular}

Table 8 shows the relation between the level of emotional intelligence with students' levels of anxiety based on the groups of age, between 13 years old and 16 years old. Analysis of correlation between the level of emotional intelligence with the level of anxiety towards 13 years old student shows that there is significant of negative relation between both of the variables, $r=-0.73 ; p<0.01$. Besides, the analysis of correlation between the levels of emotional intelligence with the level of anxiety towards 16 years old student also shows that there is significant of negative relation with the level of anxiety, $r=-0.64 ; p<0.01$.

Table 9 shows the relation between the levels of emotional intelligence with students' levels of anxiety based on gender. The analysis of correlation between the level of emotional intelligence towards male students shows the significant of negative relation between both of the variables, $r=-0.63 ; \mathrm{p}<0.01$. 
Table 10: The relation between the levels of emotional intelligence with academic achievement among rural area students from entirely view

\begin{tabular}{lll}
\hline Variable & $\mathrm{r}$ & $\mathrm{p}$ \\
\hline Emotional Intelligence & 0.78 & $0.000^{*}$ \\
\hline$*: \mathrm{p}<0.01$ & &
\end{tabular}

Table 11: The relation between the levels of emotional intelligence with students' academic achievement based on the group of age

\begin{tabular}{lll}
\multicolumn{1}{c}{ of age } & \multicolumn{2}{c}{ Academic achievement } \\
& ---------- \\
Variable & r & p \\
\hline 13 years old Student & 0.85 & $0.000^{*}$ \\
16 years old Student & 0.82 & $0.000^{*}$ \\
\hline *: $\mathrm{p}<0.01$ & &
\end{tabular}

Moreover, the analysis of correlation between the levels of emotional intelligence with the level of anxiety towards the group of female students shows that there is significant of negative relation, $r=-0.52 ; \mathrm{p}<0.01$.

The relationship between the levels of emotional intelligence with academic achievement among rural area students: Table 6-10 shows the relation between the levels of emotional intelligence with academic achievement among rural area students from entirely view. The analysis of correlation between the levels of emotional intelligence with students' academic achievement from entirely view shows that there is significant of positive relation among the entirely students, which has become the subject of the study, $\mathrm{r}=0.78 ; \mathrm{p}<0.01$.

Table 11 shows the relation between the levels of emotional intelligence with students' academic achievement based on the category of group's age between 13 years old and 16 years old. The analysis of correlation between the levels of emotional intelligence with students' academic achievement towards the group of 13 years old student shows that the emotional intelligence's levels of 13 years old student has the significant of positive relation with academic achievement, $r=0.85 ; \mathrm{p}<0.01$. Besides, the analysis of correlation between the levels of emotional intelligence with students' academic achievement towards the 16 years old student shows the significant of positive relation, $\mathrm{r}=0.82, \mathrm{p}<0.01$.

Table 12 shows the relation between the levels of emotional intelligence with students' academic achievement based on their gender. The analysis of correlation between the levels of emotional intelligence with the academic achievement of male student shows the significant of positive relation for both variables, $\mathrm{r}=0.79 ; \mathrm{p}<0.01$. Furthermore, the analysis of correlation between the levels of emotional intelligence with the academic achievement of male student shows the significant of positive relation for both variables, $\mathrm{r}=0.76 ; \mathrm{p}<0.01$.
Table 12: The relation between the levels of emotional intelligence with students' academic achievement based on gender

\begin{tabular}{lll}
\hline & \multicolumn{2}{c}{ Academic achievement } \\
Variable & r & $\mathrm{p}$ \\
\hline Male & 0.79 & $0.000^{*}$ \\
Female & 0.76 & $0.000^{*}$ \\
\hline * $\mathrm{p}<0.01$ & &
\end{tabular}

Table 13: The relation between the levels of anxiety with the academic achievement among the rural areas' students from the entirely view

\begin{tabular}{|c|c|c|}
\hline \multirow[b]{2}{*}{ Variable } & \multicolumn{2}{|c|}{ Academic achievement } \\
\hline & $\mathrm{r}$ & $\mathrm{p}$ \\
\hline Anxiety & -0.70 & 0.000 * \\
\hline
\end{tabular}

The relation between the levels of anxiety with the academic achievement among the rural area students: Table 13 shows the relation between the levels of anxiety with the academic achievement among the rural area students from the entirely view. The analysis of correlation between the levels of anxiety with the students' academic achievement from the entirely view shows the significant of negative relation, $\mathrm{r}=-0.70 ; \mathrm{p}<0.01$.

The relation between the levels of anxiety with the students' academic achievement also had been analyzed based on the group of age among 13 years old student and 16 years old student, as well as in the Table 14 . The analysis of correlation between the levels of anxiety with the academic achievement of 13 years old students' group found that the levels of anxiety of 13 years old student has the significantly negative relation in academic achievement, $\mathrm{r}=-0.65 ; \mathrm{p}<0.01$. The result of study also found the equivalent value of correlation between the levels of anxiety with academic achievement among the group of 16 years old students, which shows the significantly negative relation for both variables, $r=-0.65 ; p<0.01$.

Table 15 shows the relation between the levels of anxiety with the students' academic achievement based on gender. The analysis of correlation between the levels of anxiety with the academic achievement of female student shows the significantly negative relation for both variables, $\mathrm{r}=-0.76 ; \mathrm{p}<0.01$. Besides, the analysis of correlation between the levels of emotional intelligence with the academic achievement towards the group of female students shows the significantly negative relation with academic achievement, $r=-0.57$; $\mathrm{p}<0.01$. 
Table 14: The relation between the levels of anxiety with students' academic achievement based on the group of age

\begin{tabular}{lll}
\hline & \multicolumn{2}{c}{ Academic achievement } \\
Variable & $\mathrm{r}$ & $\mathrm{p}$ \\
\hline 13 years old Student & -0.65 & $0.000^{*}$ \\
16 years old Student & -0.65 & $0.000^{*}$ \\
\hline *: $\mathrm{p}<0.01$ & &
\end{tabular}

Table 15: The relation between the levels of anxiety with students' academic achievement based on gender

\begin{tabular}{lll}
\hline & \multicolumn{2}{c}{ Academic achievement } \\
Variable & $\mathrm{r}$ & $\mathrm{p}$ \\
\hline Male & -0.76 & $0.000^{*}$ \\
Female & -0.57 & $0.000^{*}$ \\
\hline$* \mathrm{p}<0.01$ & &
\end{tabular}

\section{DISCUSSION}

The Difference of emotional intelligence's level based on students' age: The entirely result of study shows there is no significant difference towards the emotional intelligence's level of 13 years old student and 16 years old student. The analysis of difference of emotional intelligence's level among male students shows that there is no significant difference towards 13 years old male student and 16 years old male student. The study result by Harrod dan Scheer ${ }^{[19]}$ apparently parallel with this study results. Harrod Dan Scheer ${ }^{[19]}$ found that the level of emotional intelligence does not shows the significant relation with age. The score of emotional intelligence's level with the factor of age is not interconnected and each variable exists without limitation.

However, there is significant difference between the emotional intelligence's level of 13 years old female student and 16 years old female student. Ciarrochi et al. ${ }^{[24]}$ state that the emotional intelligence of the individual should increases in parallel with the increase of their age and experience, as well as the other cognitive skills. There is also positive and significant relation between the emotional intelligence with someone age ${ }^{[1,24]}$.

The difference of emotional intelligence's level based on students' gender: The study shows there is a significant difference towards the mean score of the emotional intelligence's level among male student and female student from entirely view. Most of the result of study towards the variable is apparently show that there is significant difference regarding to the emotional intelligence's level between male and female. This study also supports the result of study by Goleman ${ }^{[17]}$, which is also found that women are wiser on self emotion, empathy in interpersonal relation compared to men. The group of female students has the highly awareness on their emotion compared to male students ${ }^{[6,7]}$. Burton et al.$^{[11]}$ also found out that female students have the highly score than male students, within interpersonal skills such as the empathy aspect, social responsibility and interpersonal relation.

The relation between the levels of emotional intelligence with the levels of anxiety among rural students: The result of study shows that the level of emotional intelligence has the significantly negative relation with students' level of anxiety. Ciarrochi Dan Scott ${ }^{[14]}$ found that the subject who has faces the difficulty to recognize a problem is actually has a close relation with anxiety's problem. The ability to recognize this problem is regarding to the emotional intelligence as stated by Bastians et al. ${ }^{[8]}$, which is the high level of emotional intelligence will show the increase in the ability to solve a problem and the ways of it management.

The high level of emotional intelligence will decrease the levels of anxiety ${ }^{[10]}$. Summerfeldt et al.$^{[35]}$ has correlates the emotional intelligence with the anxiety of social interaction and found out that the high level of emotional intelligence will decrease the anxiety within interaction. The related studies apparently support the view on the important of emotional intelligence, which has becomes the unique contributor towards the arrangement of psychological according to the level of anxiety.

The relation between the levels of emotional intelligence with the academic achievement among the rural student: The entirely study's result on the relation between the levels of emotional intelligence with the academic achievement shows that there is firmly and significantly relation to each variable, such as level of age and gender. The result of the analysis shows that the level of emotional intelligence is closely related with the level of students' academic achievement. However, the cause of both variables still cannot be determined with only based on the analysis of correlation. The study by Parker et al..$^{[26-28]}$ and Petrides et al. ${ }^{[28]}$ shows the emotional intelligence has the close and significant relation with students' academic achievement.

Moreover, the importance of emotional intelligence towards students' academic achievement can be seen in the study by Barchard ${ }^{[5]}$, which found that there are several aspects in emotional intelligence which had 
been proved in predicting the successful of students' academic. The longitudinal study by Marshmallow ${ }^{[4]}$ shows the important implication towards the relation between emotional intelligence with students' academic achievement, which found that the children with high emotional intelligence acquires the high marks compared to the children with low emotional intelligence in scholastic assessment test (ujian SAT).

The relation between the levels of anxiety with the academic achievement among the rural area students: The result of study shows that the emotional intelligence is certainly has a close relation with the levels of anxiety of a student. Besides, the existence of anxiety in individual self also influences the academic achievement of the student. The result of study entirely shows the significant negative relation among the students' levels of anxiety with their academic achievement. The values of correlation which had been found among the students' levels of anxiety with their academic achievement for each variables; the age group and the gender, are around -0.57 until -0.70 .

The result of study by Chapell et al. ${ }^{[12]}$ also found that there is significant negative relation between the analysis of anxiety with students' Cumulative Grade Point (CGPA). The students which encounter with the symptom of highly anxiety will be faced with the difficulties in study, the difficulties in using or transferring their knowledge and the difficulties in applying their knowledge in examination ${ }^{[33]}$. The result from the decrease of anxiety among children will brings them to the increase of their academic achievement at school, as well as their social function $^{[37]}$.

Implication of the study: In education field, emotional intelligence has a large implication especially in ensuring the students' ability to compete in their life and self development. Thus, the education of a new era should face this challenge and problem by preparing a curriculum, which is able to develop credibility and personality among the students. This objective can be reach through the introduction of programs which is not only based on academic, but also emphasizing on the skill of making a decision and developing students' self concept.

In the professionalism of educators' contexts, the educators should always increase the stability of students' emotion through their keen on accept and listen to the sigh and problem of the students. Hence, the paradigm shift among the educator is intensely needed. This result also shows that the individual's success should not be measured basically based on the aspect of academic, but also on non-academic. They need to realize that the ability to manage their emotion is one of important elements in determining the success of individual's life ${ }^{[17]}$.

Even though the anxiety is a condition of emotion that happens at an internal level of student, it is also becomes one of problem's behavior which is less extruded on its problematic. The high level of anxiety is a phenomenon that will cause a negative personality among children. They will face a trouble in their relation with others (May, 1996).

Suggestion: Teachers should acquire a skill to exploit the advantages at each dimension of students' emotional intelligence. Thus, they should have knowledge of emotional intelligence, so that they can help to develop the emotional intelligence among their students. Moreover, students should be taught on the strategy to handle the problem of emotion and the way to cooperate with others by their teachers. When students are able to control their emotion, they can concentrate towards their study's process.

Teachers should also generate a pleasurable classroom, by having a group discussion to a give a chance towards students to interact simultaneously. Through this, the students are able to identify the feeling of their friends and get the feedback based on their reaction by construct the feeling of empathy. Furthermore, teachers can apply several strategies to reduce the negative effect of students' anxiety in each learning process by constructing an acceptable and pleasurable condition, which is able to give a support to the students ${ }^{[33]}$.

Besides, teacher can reduce the problem of anxiety among the students by helping them to increase the low level of self efficacy ${ }^{[3]}$. The low level of self efficacy will increase the anxiety in their selves. When they feel that they are able to handle a task, they are less anxious in doing it. In addition, students should be given more bareness regarding the skill or the technique to reduce their anxiety. The teachers can also play their role with helping the students which had been encountered with a high level of anxiety, by practicing an actively teaching and learning method in class, such as collaborative learning, cooperative learning and learning process based on problem.

Suggestion for continuation study: An entirely study should be suggested to study the relation between emotional intelligence with the factor of anxiety and students' academic achievement. The detailed study is suggested so that the sample of the study can be obtained from many schools. A broad study can be 
done towards each forms to identify how far the relation between the emotional intelligence with the increase of students' academic achievement and their age. Thus, teachers can obtain the knowledge and skill on the level of emotional intelligence among their students. This kind of study is hoped to be carried out from time to time according to the need. The comparison can be done between the emotional intelligence and cognitive intelligence, as well as its implication towards academic achievement and students' behavior. This result might giving a clear description regarding the dominantly factor, which is influencing the aspect of academic achievement and students' behavior.

This study basically based on the variable of the emotional intelligence and the aspect of anxiety, as well as students' academic achievement only. The series of additional study can be done by focusing on the other aspects, such as thinking skills and managing strain skills, which are directly relate with students' emotional intelligence. Several variables should be considered such as the condition of schools, socioeconomic status and the role of parents especially from the aspects of education style, the concept of self student and the factor of teacher. The study towards the aspect of emotional intelligence is still new. Therefore, the result of this study is hoped to be able to inspire many researchers to give their intention towards the study of emotional intelligence.

\section{CONCLUSION}

In conclusion, emotional intelligence is seen as one of main elements in individual's life according to the result of the study. In the context of Malaysia, the aspect of emotional intelligence is primarily focused in The National Philosophy of Education. In realizing the reality, the curriculum of education within primary school, secondary and higher education needs to be planned by concerning to the aspect of emotional intelligence. However, regarding to the relation between emotional intelligence with the level of anxiety and students' academic achievement, the correlation study which had been used cannot be taken as the firmly proof to shows the basis of each variable. According to Jackson, Sherri ${ }^{[36]}$, correlation is not certainly based on the cause, but has a peculiar objective and it is very useful in determining the relation between the variables, as well as suggesting the fundamental or the basis which might be exist regarding to the relation of cause and consequence.

However, the efforts to implement the emotional intelligence in ensuring the accomplishment and the development of students' self should be executed intellectually. This responsibility should not be bearded only by the teachers, but the most important is the need of paradigm shift in the system of education together with professionalism of education. The policymaker of education should arrange the liberty and an approach, as well as the firmly support, to ensure the balance of national education's system from the aspect of emotional intelligence and intellectual intelligence.

\section{REFERENCES}

1. Atkins, P. and C. Stough, 2005. Does emotional intelligence change with age? Paper presented at the Society for research in Adult Development Annual Conference, Atlanta, GA.

2. Azizi Yahaya, Asmah Suboh, Zurihanmi Zakariya and Fawziah Yahya, 2005. Cognitive Application in Education. PTS Professional Publishing, Sdn. Bhd., Bentong, ISBN: 983-3376-01-0, pp: 347.

3. Yahaya, A., C.S. Abdullah, R. Ahmad and S. Ismail, 2006. The Route Cause and Treatment of Bad Behaviors. PTS Professional Publishing, Sdn. Bhd., Kuala Lumpur, ISBN: 983-3376-81-9, pp: 307.

4. Yahaya, A., N. Yahaya and Z. Zakariya, 2005. Cognitive Psychology. University Technology Malaysia, Skudai, ISBN: 983-52-0368-7, pp: 99-119.

5. Barchard, K.A., 2003. Does emotional intelligence assist in the prediction of academic success? Educ. Psychol. Measure., 63: 840-858. DOI: 10.1177/0013164403251333

6. Bar-on, R., 1997. Bar-On Emotional Quotient Inventory (EQ-i): Technical Manual. Multi Health Systems, Toronto. www.eiworld.org/docs/EQ360short_2007.pdf

7. Barret, L.F., D. Lane, R.S. Lee and E.S. Gary, 2000. Sex differences in emotional awareness. Personal. Soc. Psychol. Bull., 26: 1027-1035. DOI: 10.1177/01461672002611001

8. Bastian, V.A., R.B. Nicholas and N. Ted, 2005. Emotional intelligence: Predicts life skills, but not as well as personality and cognitive abilities. Personal. Indiv. Differ., 39: 1135-145. DOI: 10.1016/j.paid.2005.04.006

9. Beck, A.T., N. Epstein, G. Brown and R. Steer, 1988. An inventory for measuring anxiety: Psychometric properties. J. Consul. Clin. Psychol., 56: 893-897. DOI: 10.1037/0022-006X.56.6.893

10. Brown, R.F. and S.S. Nicola, 2006. Direct and indirect relationships between emotional intelligence and subjective fatigue in university students. J. Psychosomat. Res., 60: 585-593. DOI: 10.1016/j.jpsychores.2006.05.001

11. Burton, L.A., H. Jessica and H. Debra, 2007. Gender differences in relational and physical aggression. Soc. Behav. Personal., 35: 41-50. DOI: 10.2224/sbp.2007.35.1.41 
12. Chapell, M.S., Z.B. Benjamin, S.E. Micheal, T. Masami, N. Brian, G. Aaron and M. Nicole, 2005. Test anxiety and academic performance in undergraduate and graduate students. J. Educ. Psychol., 97: 268-274.

http://cat.inist.fr/?aModele $=$ afficheN\&cpsidt $=16801649$

13. Chapman, B.P. and H. Bert, 2005. Incremental validity of a measure of emotional intelligence. J. Personal. Assess., 85: 154-169. http://cat.inist.fr/?aModele $=$ afficheN\&cpsidt $=17174265$

14. Joseph, C. and S. Greg, 2006. The link between emotional competence and well-being: $\mathrm{A}$ longitudinal study. Br. J. Guid. Counsell., 34: 231-243. DOI: 10.1080/03069880600583287

15. Clark, M.S. and S.T. Fiske, 1982. Affect and Cognition. De Ayala, Vonderhaurr, Hillsdale, NJ: Lawrence Erlbaurm, pp: 333-342.

16. De Ayala, R.J., D.J. Vonderhaur-Carlson and D. Kim, 2005. Assessing the reliability of the beck anxiety inventory scores. Educ. Psychol. Measure., 65: 742-756. DOI: $10.1177 / 0013164405278557$

17. Goleman, D., 1998, Working With Emotional Intelligence. 1st Edn., Bloomsbury Publishing, London, ISBN: 978-0553378580.

18. Hardy, L. and C.G. Parfitt, 1991. A catastrophe model of anxiety and performance. Br. J. Psychol., 82: 163-178.

http://www.ncbi.nlm.nih.gov/pubmed/1873650

19. Harrod, N.R. and D.S. Scott, 2005. An exploration of adolescent emotional intelligence in relation to demographic characteristics. Adolescence, 40: 503-512. http://cat.inist.fr/?aModele $=$ afficheN\&cpsidt $=17239970$

20. Hurlock, E.B., 1973. Adolescent Development. Mc Graw Hill, Inc., London, ISBN: 0070314578.

21. Ma'rof, R. and H. Abdullah, 2001. Psikologi. Mc Graw Hill, Kuala Lumpur, pp: 170-174.

22. MacCann, C., G. Matthews, M. Zeidner and R.D. Roberts, 2003. Psychological assessment of emotional intelligence: A review of self-report and performance-based testing. Int. J. Org. Anal., 11: 247-274. DOI: $10.1108 / \mathrm{eb} 028975$

23. Mayer, J.D. and P. Salovey, 1993. The intelligence of emotional intelligence. Intelligence, 17: 433-442.

http://cat.inist.fr/?aModele $=$ afficheN\&cpsidt=3977 197

24. Joseph, C. and J.D. Mayer, 2007. Applying Emotional Intelligence. A Practitioner's Guide. Psychology Press, New York, ISBN: 1-84169-4622, pp: 53-88.

25. Hamid, M.A.A., 2006. The Way to Improve Emotional Intelligence. 3rd Edn., PTS Professional Publishing, Batu Caves, ISBN: 983-3585-15-9, pp: 252.
26. Parker, J.D.A., E.C. Ronald, L.B. David, J.I. Harris, S.A. Majeski, L.M. Wood, B.J. Barbara and J.H. Marjorie, 2004. Academic achievement in high school: Does emotional intelligence matter? Personal. Indiv. Differ., 37: 1321-1330. http://cat.inist.fr/?aModele $=$ afficheN\&cpsidt $=16209401$

27. Parker, J. D.A., J.H. Marjorie, M.E. Jennifer, A. Oke, and M.W. Laura, 2006. Emotional intelligence and student retention: Predicting the successful transition from high school to university. Personal. Indiv. Differ., 41: 1329-1336. DOI: 10.1016/j.paid.2006.04.022

28. Petrides, K.V., N. Frederickson and A. Furnham, 2004. The role of trait emotional intelligence in academic performance and deviant behavior at school. Personal. Indiv. Differ., 36: 277-293. http://direct.bl.uk/bld/PlaceOrder.do?UIN=142036 $653 \&$ ETOC $=$ RN\& from $=$ searchengine

29. Salovey, P. and J.D. Mayer, 1990. Emotional intelligence. Imaginat. Cognit. Personal., 9: 185-211.

30. Schutte, N.S., J.M. Malouff, L.E. Hall, D. Haggerty, J.T. Cooper, C. Golden and L. Dornheim, 1998. Development and validation of a measure of emotional intelligence. Personal. Indiv. Differ., 25: 167-177. DOI: 10.1016/s0191-8869(98)0001-4

31. Schutte, N.S., J.M. Malouff, M. Simunek, J. McKenley and S. Hollander, 2002. Characteristic emotional intelligence and emotional well-being. Cognit. Emotion., 16: 769-785. DOI: $10.1080 / 02699930143000482$

32. Noah, S.M., 2002. Research Methodology: Philosophy, Theory and Practice. University Putra Malaysia, Serdang, ISBN: 983-2373-38-7, pp: 85-96.

33. Slavin, R.E., 2006. Educational Psychology: Theory and Practice. 8th Edn., Pearson Education, Inc., Boston, ISBN-10: 0205470998, pp: 609.

34. Spielberger, C.D., 1972. Anxiety: Current Trends in Theory and Research. Academic Press, New York, ISBN: 0126574014.

35. Laura J.S., P.H. Kloosterman, M.M. Anthony and J.D.A. Parker, 2006. Social anxiety, emotional intelligence and interpersonal adjustment. J. Psychopathol. Behav. Assess., 28: 57-68. DOI: 10.1007/s10862-006-4542-1

36. Jackson, S.L., 2003. Research Methods and Statistics: A Critical Thinking Approach. Wadsworth/Thomson Learning, Belmont, ISBN: 0-534-55423-7, pp: 49-65.

37. Wood, J., 2006. Effect of anxiety reduction on children's school performance and social adjustment. Develop. Psychol., 42: 345-349. http://cat.inist.fr/?aModele $=$ afficheN\&cpsidt $=17641403$ 